Bangladesh J. Bot. 47(4): 877-885, 2018 (December)

\title{
POTENTIAL OF TRAGACANTH GUM AS GELLING MATERIAL IN PLANT TISSUE CULTURE STUDIES
}

\author{
Cigdem Alev Ozel ${ }^{*}$, Fatma Unal $^{1}$ and Deniz Yuzbasioglu ${ }^{1}$ \\ Department of Biology Education, Faculty of Gazi Education, Gazi University, \\ Teknikokullar, 06500 Ankara, Turkey
}

Keywords: Tragacanth gum, Germination, Morphogenesis, Chromosome number, Tissue culture

\begin{abstract}
The diffusion ability and rheological properties of MS medium for germination and growth of tobacco seedlings of cv. Samsun Canik at different $\mathrm{pH}$ and concentrations of tragacanth gum were compared. The results showed that $11 \mathrm{~g} / \mathrm{l}$ tragacanth gum with low osmotic pressure at $\mathrm{pH} 5.6$ 5.8 offered the best conditions for morphological developments like longer shoots, roots and broader leaves of the seedlings compared to the similar morphological developments on agar solidified MS medium with high osmotic pressure. No aberration was noted in nulmber of chromosomes of germinated tobacco seedlings on either agar or tragacanth containing medium. On the basis of present findings, it is possible to suggest that tragacanth gum had high potential to replace agar in seed germination studies.
\end{abstract}

\section{Introduction}

Plant cell and tissue culture are widely used to propagate plant species on gelling matrices containing plant growth regulators supplemented with sucrose and basal medium to multiply plants. Gelling matrices hold and support the plants during growth in culture cabs and dishes. Most popular gelling matrices to hold tissue cultured plants include agar that provides a solid or semi solid nutrient containing matrix which is easy to use, nontoxic and has a number of advantages compared to other gelling matrices (McLachlan 1985, Henderson and Kinnersley 1988, Sudha 2017). The characteristic of agar varies depending on chemical constituents and the age of mother weeds (Debergh 1983, Nairn et al. 1995, Sulusoglu 2014, Lee et al. 2017). Consequently, these affect their rate of propagation. Agar is a traditional solidifying matrix that composed of sugar monomers, D- and L-galactose, and polysaccharide in nature (Azarikia and Abbasi 2010, Parashar et al. 2013). Agar is imported globally using a large amount of foreign exchange, therefore, researchers must identify appropriate alternatives to this drain.

Some replacements like glass beads (Goel et al. 2007), isubgol in algal studies or mixtures of isubgol and agar (Atici et al. 2008), phytagel, gelrite (Ozel et al. 2008), potato extract (Dalvi et al. 2011), cotton wool (Dalvi et al. 2011), cassava starch-agar blend (Saglam and Ciftci 2010, Kwoseh et al. 2012), miconazole nitrate gel (Parashar et al. 2013), luffa coir and guar gum as liquid media support (Hussien et al. 2014) have been suggested as alternatives in plant tissue culture. Recently Karimi et al. (2016) have recommended the use of tragacanth in Carnation and Miniature Rose tissue culture media.

Stable textured tragacanth gum is primarily used as a suspending agent in mixtures containing resins, heavy insoluble powders and volatile oils in the British Pharmacopoeia (Delease 2008). It is also widely used as food, medicinal, and industrial applications (Abbasi and Rahimi 2015, Teimouri et al. 2016). The Panel on Food Additives and Nutrient Sources made a decision that there is no requirement for a numerical ADI for tragacanth (E413) and that there is no safety concern for public at the refined exposure evaluation of tragacanth as a food additive (Mortensen et al. 2017).

\footnotetext{
*Author for correspondence: <cigdemozel@gazi.edu.tr>. ${ }^{1}$ Department of Biology, Faculty of Science, Gazi University, Teknikokullar, 06500 Ankara, Turkey.
} 
Tragacanth is a complex mixture of galactoarabans and acidic polysaccharides (Phillips and Williams 2009), which upon hydrolysis yields D-galacturonic acid, D-galactose, L-fucose (6deoxy-L-galactose), D-xylose, and L-arabinose, D-galacturonic acid methylester (Mohamadnia et al. 2008). The acidic components are largely present as calcium, magnesium, and potassium salts. The gum also contains trace amounts of amino acids and their derivatives. It has a molecular weight of about 840,000 Dalton and an elongated shape of $4500^{\circ} \mathrm{A} \times 19^{\circ} \mathrm{A}$ for a flake type of nondegraded gum (Weiping 2000, Mohamadnia et al. 2008).

Tragacanth is considered to contain two primary constituents; tragacanthin and bassorin, both of which are insoluble in alcohol and have high molecular weights (Weiping 2000, Balaghi et al. 2011). The minor component, tragacanthin, is a highly branched arabinogalactan and is soluble in water to give a colloidal hydrosolution (gel). The tragacanthin and bassorin polysaccharidesare physically mixed in tragacanth gum without any chemical bonding (Lapasin and Pricl 1995, Balaghi et al. 2011).

The present paper aims to evaluate the possible effects of tragacanth gum as a potential gelling matrix by comparing with standard agar and by investigating morphological and cytogenetic changes on behavior of post seed germinated plants of tobacco cv. Samsun Canik.

\section{Materials and Methods}

The seeds of Nicotiana tabaccum cv. Samsun Canik were subjected to surface strelization by immersing them in $30 \%$ solution of commercial bleach (ACE Turkey, $3 \% \mathrm{NaOCl}$ ) for $5 \mathrm{~min}$. Thereafter, they were rinsed in autoclaved distilled water for $3 \times 3 \mathrm{~min}$. The seeds were cultured on MS medium supplemeted with $30 \mathrm{~g} / 1$ sucrose and solidified with $7-15 \mathrm{~g} / \mathrm{l}$ pure tragacanth gum and $7 \mathrm{~g} / \mathrm{l}$ agar (control) for gelling.

Tragacanth was obtained from Astragalus microcephalus Wild. which was supplied by Prof. Dr. K. M. Khawar of the Department of Field Crops, Ankara University, Turkey. Agar used in the study was purchased from Sigma Aldrich (St. Lo Mo USA). Germination medium was autoclaved at $121^{\circ} \mathrm{C}$ under $104.5 \mathrm{kPa}$ pressure for $20 \mathrm{~min}$. The $\mathrm{pH}$ of all medium was adjusted to $4.4-4.6 / 4.7$ - 4.9/5.0 - 5.2/5.3 - 5.5/5.6 - 5.8 with $1 \mathrm{~N} \mathrm{HCl}$ or $1 \mathrm{~N} \mathrm{NaOH}$ before autoclaving. All concentrations were mixed thoroughly after autoclave and before pouring each of the molten gelling matrixes into Petri dishes. All cultures were maintained at $24 \pm 1^{\circ} \mathrm{C}$ under white fluorescent light of 6000 lux in Sanyo environmental growth chambers maintaining $16 \mathrm{hrs}$ light photoperiod. The tobacco seedling cultures were incubated for 8 weeks.

Following germination all experimental data were analyzed using one-way ANOVA of IBM SPSS 22 statistical software. The post hoc tests were performed using Tuckey's multiple range test with comparison made at 0.05 level of significance. In total 300 seeds were used for each experimental treatment. The treatments were arranged in completely randomized design. Each treatment was divided into 3 replicate groups containing 10 explants per replication.

After germination of seeds in nine concentrations $(7-15 \mathrm{~g} / \mathrm{l})$ of tragacanth gum and agar (control) gelling matrices, $0.5 \mathrm{~cm}$ long root tips were thoroughly washed to remove adhering gel. Root tips were pre-treated in $\alpha$-bromonaphthaline for $12 \mathrm{hrs}$ and fixed in 3:1 (alcohol:acetic acid) for $16 \mathrm{hrs}$, followed by their storage in $70 \%$ alcohol until use. These were hydrolyzed in $1 \mathrm{~N} \mathrm{HCl}$ for $25 \mathrm{~min}$ at $60^{\circ} \mathrm{C}$ and stained in Feulgen for $1 \mathrm{hr}$. Squash preparation was made in acetocarmine. The cover slip was removed by freezing in liquid nitrogen and the slide was thoroughly air dried to make permanent mounting in Entellan. At least five root cells of plants cultured on each of the MS medium solidified with nine concentrations of tragacanth gelling matrix and agar (control) were critically analyzed under the light microscope for the number of chromosomes. 


\section{Results and Discussion}

Comparing three tested $\mathrm{pH}$ ranges described above, gelling at $\mathrm{pH}$ ranges of $4.4-4.6 / 4.7$ 4.9/5.0 - 5.2 and $5.3-5.5$ had variably poor solidification after autoclaving. This made it difficult to hold the seedlings to grow with increased hyperhydricity and necrosis. $\mathrm{pH}$ ranges of $5.6-5.8$ showed the best solidification/gelling irrespective of the concentration without showing any signs of hyperhydricity (Data about $\mathrm{pH}$ ranges of 4.4 - 4.6/4.7 - 4.9/5.0 - 5.2/5.3 - 5.5 not given). When $\mathrm{pH}$ of a holding matrix dropped below 5.6 - 5.8 retarding growth of roots and plants were noted. This might be due to restricted availability of water and nutrients that resulted in abnormal growth or necrosis on roots, shoots and morphogenesis.

The results clearly showed that different concentrations of tragacanth gum used as gelling agent had apparently different effects on frequency of shoot regeneration, rooting percentage, leaf length and number of leaves per explant (Table 1, Fig. 1). The Fig. 1a showed seedling development on agar. The best seedling growth was noted on $11 \mathrm{~g} / 1$ tragacanth gum (Fig. 1b). Minimum seedling development on tragacanth containing medium was noted on $15 \mathrm{~g} / \mathrm{l}$ (Fig. 1c).

Table 1. Effects of MS medium solidified with different tragacanth gum concentrations on seeds germination and growth of Nicotiana tabaccum cv. Samsun Canik.

\begin{tabular}{llllll}
\hline $\begin{array}{l}\text { Tragacanth gum } \\
(\mathrm{g} / \mathrm{l})\end{array}$ & $\begin{array}{l}\text { Average shoot } \\
\text { length }(\mathrm{cm})\end{array}$ & $\begin{array}{l}\text { Average root } \\
\text { length }(\mathrm{cm})\end{array}$ & $\begin{array}{l}\text { Average number } \\
\text { of leaves/plant }\end{array}$ & $\begin{array}{l}\text { Average leaf } \\
\text { length }(\mathrm{cm})\end{array}$ & $\begin{array}{l}\text { Average leaf } \\
\text { width }(\mathrm{cm})\end{array}$ \\
\hline 7 & $13.34 \mathrm{ab}$ & $3.19 \mathrm{c}$ & 9.08 & $2.09 \mathrm{ab}$ & $1.06 \mathrm{ab}$ \\
8 & $11.67 \mathrm{ab}$ & $2.79 \mathrm{c}$ & 8.50 & $2.20 \mathrm{ab}$ & $1.15 \mathrm{ab}$ \\
9 & $11.47 \mathrm{ab}$ & $2.25 \mathrm{c}$ & 8.17 & $2.15 \mathrm{ab}$ & $1.04 \mathrm{ab}$ \\
10 & $11.49 \mathrm{ab}$ & $2.32 \mathrm{c}$ & 8.17 & $2.39 \mathrm{ab}$ & $1.10 \mathrm{ab}$ \\
11 & $17.00 \mathrm{a}$ & $8.54 \mathrm{a}$ & 10.50 & $3.14 \mathrm{a}$ & $1.47 \mathrm{a}$ \\
12 & $13.65 \mathrm{ab}$ & $7.38 \mathrm{ab}$ & 9.92 & $2.11 \mathrm{ab}$ & $1.06 \mathrm{ab}$ \\
13 & $10.54 \mathrm{~b}$ & $7.78 \mathrm{ab}$ & 8.22 & $1.93 \mathrm{~b}$ & $1.02 \mathrm{ab}$ \\
14 & $8.81 \mathrm{~b}$ & $5.75 \mathrm{~b}$ & 8.75 & $2.70 \mathrm{ab}$ & $1.31 \mathrm{ab}$ \\
15 & $8.01 \mathrm{~b}$ & $2.96 \mathrm{c}$ & 10.67 & $0.93 \mathrm{c}$ & $0.46 \mathrm{~b}$ \\
Control $(7 \mathrm{~g} / \mathrm{l}$ agar $)$ & $8.75 \mathrm{~b}$ & $2.58 \mathrm{c}$ & 9.08 & $0.88 \mathrm{c}$ & $0.44 \mathrm{~b}$ \\
\hline
\end{tabular}

Values within column by different letters are significantly different at the 0.05 level by Tukey's b-test. Values within column followed by no letters are not significantly different by Tukey's b test

Average shoot length ranged from 8.01 to $17.00 \mathrm{~cm}$. Comparing shoot length on two gelling agents, minimum shoot length was noted on agar and maximum on $11 \mathrm{~g} / \mathrm{l}$ tragacanth gum solidified medium (Fig. $1 \mathrm{~d}$-e). The plantlets germinated on agar showed significantly reduced length compared to the shoot length noted on all strengths of tragacanth gum. Gelling with $>12$ $\mathrm{g} / \mathrm{l}$ tragacanth gum had visible negative effects on gaining shoot length. Average root length ranged between 2.25 and $8.54 \mathrm{~cm}$. Again, the maximum root length was recorded following $11 \mathrm{~g} / \mathrm{l}$ tragacanth gum concentration. The minimum or $<3.19 \mathrm{~cm}$ root length was observed after $7,8,9$, 10 , and $15 \mathrm{~g} / 1$ tragacanth gum concentrations.

Average number of leaves per explant increased by using 11, 12 and $15 \mathrm{~g} / 1$ tragacanth gum gelling medium. Maximum number of leaves per explant was recorded as 10.67 on $11 \mathrm{~g} / \mathrm{l}$ tragacanth gum. However, no statistical difference was recorded between different tragacanth gum concentrations and control in the average number of leaves per explant. Similarly, the leaves on 
$15 \mathrm{~g} / 1$ tragancanth were partially chlorotic but their number was statistically similar to the number of leaves noted on $7 \mathrm{~g} / 1$ agar in MS medium.

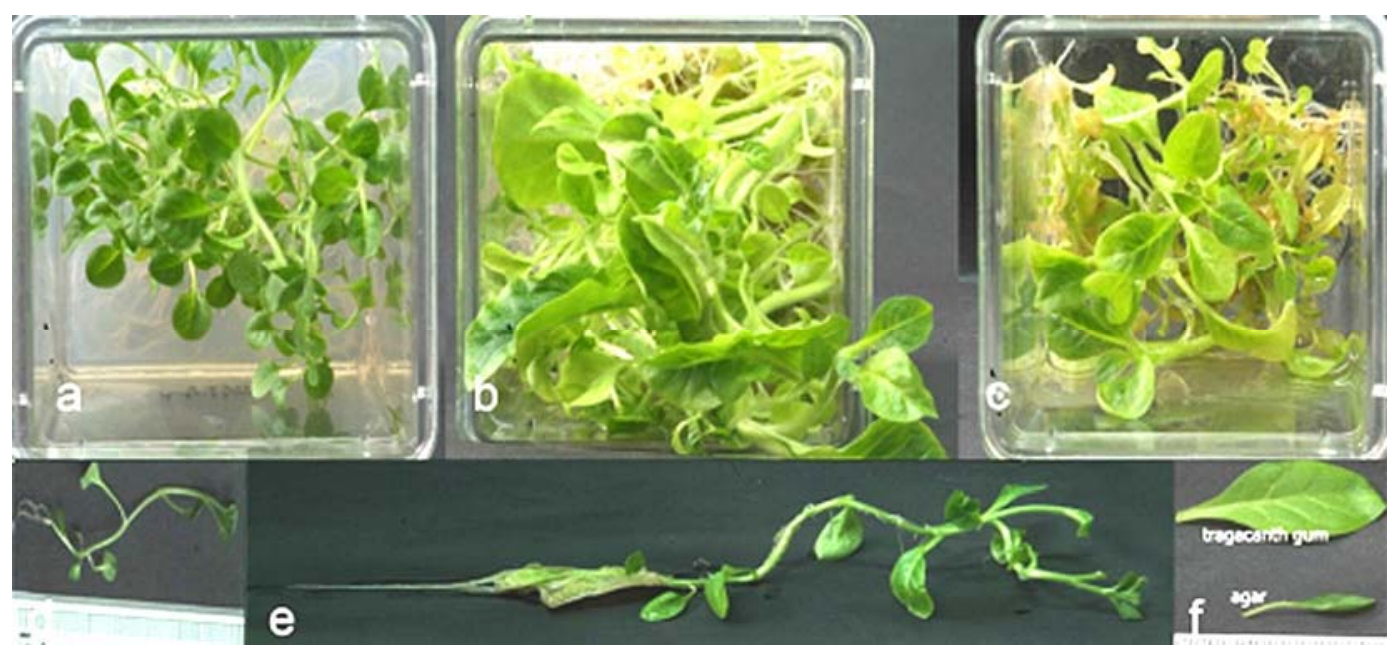

Fig. 1. Germination of tobacco cv. Samsun Canik on (a) agar, (b) $11 \mathrm{~g} / 1$ tragacanth gum, (c) $15 \mathrm{~g} / 1$ tragacanth gum, (d) shoot length on agar, (e) shoot length on $11 \mathrm{~g} / 1$ tragacanth and (f) comparison of the leaf lengthon tragacanth gum $(11 \mathrm{~g} / 1)$ and $\operatorname{agar}(7 \mathrm{~g} / 1)$.

All concentrations (except 15 of g/l) of tragacanth gum used for gelling significantly increased the average leaf length compared to control. The longest $(3.14 \mathrm{~cm})$ leaves were recorded on medium gelled with $11 \mathrm{~g} / \mathrm{l}$ tragacanth gum (Fig. 1f).

Significant differences were noted among leaf widths compared to control. Maximum leaf width $(1.47 \mathrm{~cm})$ was recorded on $11 \mathrm{~g} / 1$ tragacanth gum gelling medium that was significantly different compared to the leaf width noted on control treatment containing agar. The leaves on 15 $\mathrm{g} / \mathrm{l}$ tragacanth were partially chlorotic with leaf width of $0.46 \mathrm{~cm}$ that was very similar to the leaf width on plantlets grown on agar containing MS medium.

It was assumed that the gelling agent besides giving invigoration to germinating plants could also have impacts on the growing plants by creating polyploidy. Therefore, to check any induced polyploidy on growing tobacco plants on all of nine concentrations of tragacanth, the roots were compared with the chromosomes of tobacco plants cultured on agar gelled medium. Following examinations of cells in terms of chromosome number, no cell was found to have polyploidy. All tobacco plant root cells showed $48(2 n=48)$ chromosomes regardless of their origin whether on agar (Fig. 2a) or any concentrations of tragacanth gum (Fig. 2 b,c,d) containing medium.

There are many different types of plant exudates that serve as emulsifiers and could also act as alternatives substitutes for gelling including tragacanth gum that has been studied rarely (Jain and Babbar 2002, 2005, Kuria et al. 2008, Ozel et al. 2008, Karimi et al. 2016). Properties of all gelling agents vary depending on chemical constituents and the age of mother plants and their concentration that effects in vitro germination of seeds, regeneration and rooting from the explants (Ozel et al. 2008, Shi et al. 2017). Tragacanth gum is most commonly obtained from the sap of Astragallus gummifer in Iran and Astragallus microcephalus in Turkey. It is popularly used as freeze-embed medium to preserve tissues in life science studies (Meng et al. 2014). Tragacanth gum even in low amount makes medium viscous and cause enormous increase in amount of 
viscous solutions (Nussinovitch 1997). This study aimed to evaluate the effect of different concentrations of tragacanth gum at varying $\mathrm{pH}$ ranges gelling matrix on tobacco seed germination and variation of chromosome number in root meristem.

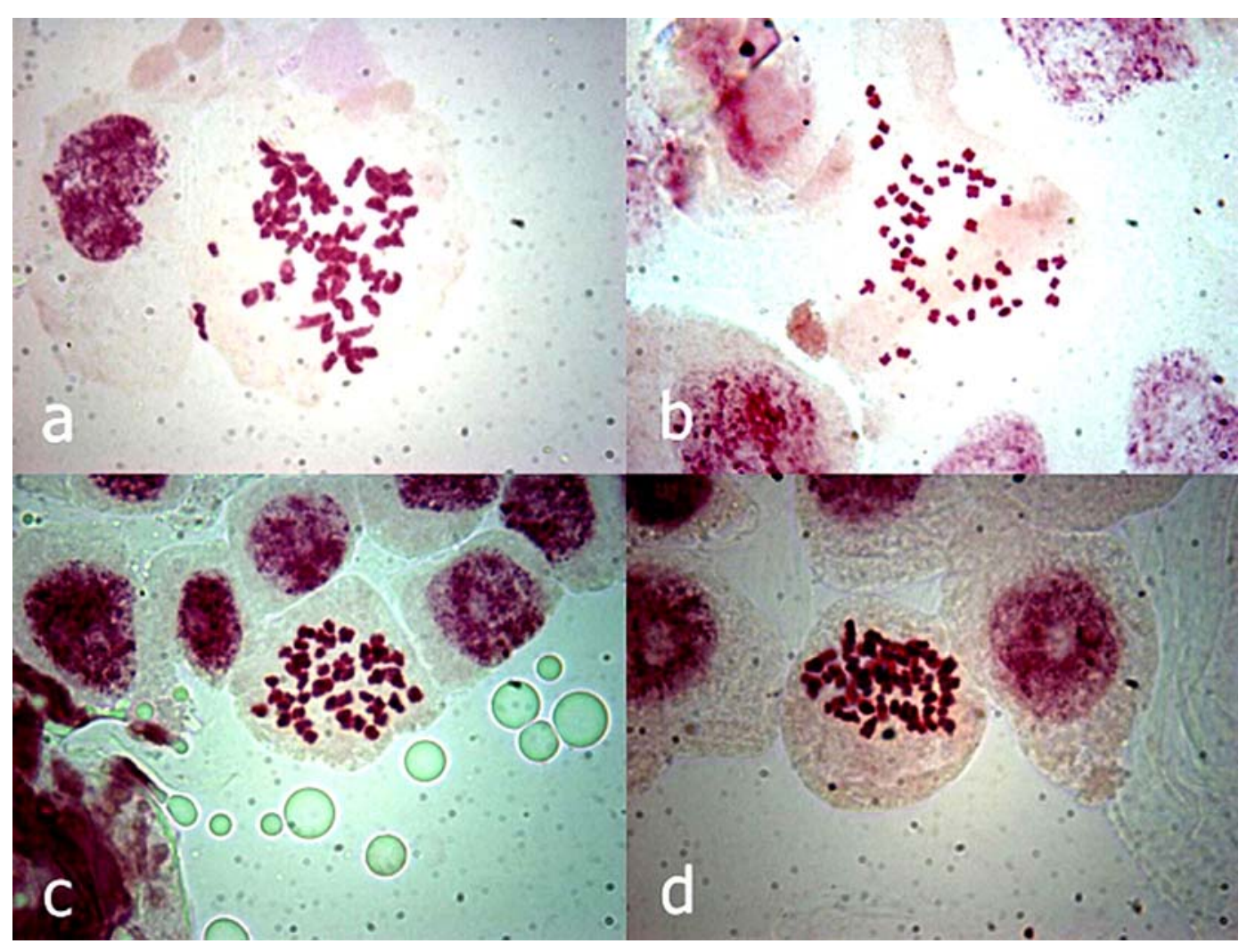

Fig. 2. Comparison of chromosomes of tobacco cv. Samsun Canik on (a) agar (control), (b) $7 \mathrm{~g} / \mathrm{l}$, (c) $11 \mathrm{~g} / \mathrm{l}$ and (d) $15 \mathrm{~g} / \mathrm{l}$ tragacanth containing gelling matrices.

All concentrations of tragacanth gum were mixed thoroughly after autoclave and before pouring each of the molten gelling matrixes into Petri dishes. This was done to avoid formation of clumps and maintain uniform viscosity of each of the gelling matrix in solution (Imeson 1992). This allowed easy holding of tobacco seedlings on the matrix.

It was noted that the tragacanth gum behaved differently at different concentrations and $\mathrm{pH}$ ranges (Glicksman 1969, Anderson 1989). It was observed that tragacanth gum reaches maximum stable viscosity at $\mathrm{pH} 5$ that decrease sharply after heating, adding alkali or acid (Mantell 1947, Schwarz et al. 1958). Contrarily, the results of this study suggested that tragacanth gelling was more stable at $\mathrm{pH}$ range of $5.6-5.8$ for tobacco seed germination compared to other $\mathrm{pH}$ ranges. The results are also in agreement with Karimi et al. (2016) who had similar pH observations on carnation and miniature rose tissue culture with tragacanth gum.During tissue culture studies, the pre-sterilization $\mathrm{pH}$ of the medium was adjusted in range of 5.6 - 5.8 to help maximum availability of mineral nutrients in the medium (Dougall 1980, Congard et al. 1986, Ozel et al. 2008, Bhojwani and Dantu 2013). A pH below 5.0 does not allow solidification of the agar. When 
$\mathrm{pH}$ of a holding matrix drops, it also retards growth of roots due to restricted availability of water and nutrients especially $\mathrm{Ca}, \mathrm{Mg}, \mathrm{P}, \mathrm{Mo}$, and $\mathrm{Si}$. These effects resulted in complication of their interaction with plants grown on that matrix and induce stress. Restricted access to water and nutrient elements leads to abnormal growth or no growth, and necrosis (Rousk et al. 2009, Xiao et al. 2014).

It was noted that concentrations $<11 \mathrm{~g} / 1$ tragacanth gum was not suitable to give appropriate strength to gels. These concentrations failed to hold the plants appropriately after germination due to achievement of lack of desired viscosity causing on the growing tobacco plantlets. No gel was observed at $6 \mathrm{~g} / \mathrm{l}$ (data not shown). The explants needed to support to prevent them from sinking. The best and optimum results (maximum shoot, root and leaf length) were observed at concentration of $11 \mathrm{~g} / \mathrm{l}$ as gelling agent. Tragacanth concentrations $>12-15 \mathrm{~g} / \mathrm{l}$ in culture medium seemed creating gradually increasing stress on germinating seedlings with high chlorosis. There were no observed hyperhydric plantlets at all treatments. Considerably poor growth was noted on agar solidified medium (control), whereas, plant growth significantly varied depending on the concentration of tragacanth gum in the medium that provided different degree of firmness. Karimi et al. (2016) used $25-40 \mathrm{~g} / \mathrm{l}$ concentrations of tragacanth gum after mixing them with $2-3 \mathrm{~g} / 1$ agar to increase the firmness of the culture medium. They noted that $25,30,35$ and $40 \mathrm{~g} / \mathrm{l}$ tragacanth gum used singly may not provide sufficient support for holding the explants. The possible reason could be use of tragacanth gum obtained from different Astragalus sources in these two studies. The osmotic stress due to chemical (MS medium, sucrose concentration) and physical factors (concentration of gelling agent, agar or tragacanth gum) used to grow tobacco seeds, affected their germination behavior. Karimi et al. (2016) noted that the best morphological growth could only be noted when both agar and tragacanth gum were mixed $(2 \mathrm{~g} / \mathrm{l}$ agar $+25 \mathrm{~g} / \mathrm{l}$ Tragacanth and $2 \mathrm{~g} / \mathrm{l}$ agar $+30 \mathrm{~g} / \mathrm{c}$ Tragacanth). Kuria et al. (2008) suggested that the frequency of hyperhydric plantlets can be reduced by using high concentrated gelling agents. Karimi et al. (2016) used higher concentrations $(25-40 \mathrm{~g} / \mathrm{l})$ of tragacanth alone, they observed hyperhydric plantlets but they noted improved performance of carnation and miniature rose plantlets on tragacanth gelled medium in high concentration of tragacanth gum mixing with agar. Kevers et al. (2004), Van den Dries et al. (2013) and Bakir et al. (2016) also reported hyperhydricity on the developing plantlets with morphological alterations like development of bushy structure or malformed growth on leaves and stems. They suggested that improper strength of the gelling agent could result in mortality of the plants as they submerge and drown variably.

The results of this study showed that seed germination started after one week following treatment while no seed had germinated on agar (control) gelled medium. The results are partially supported by the findings of Karimi et al. (2016). They observed that their plantlets started regeneration 4 to 6 days earlier on tragacanth gum compared to agar solidified medium. Significantly smaller leaves were observed on $15 \mathrm{~g} / \mathrm{l}$ tragacanth gum and $7 \mathrm{~g} / \mathrm{l}$ agar. No statistical difference was recorded among number of leaves with the range of 8.17 to 10.67. Karimi et al. (2016) recorded the best results of tragacanth media ranged between 3.1 and 5.9 leaf on carnation and 9.5 - 14.2 leaf on miniature rose. The variations between the results of this study and Karimi et al. (2016) could be due to use of the different plant species cultured and the source of tragacanth gum in the reported studies.

The reason for recording of poor plant growth on tragacanth gum and increased shoot retardation on agar might be attributed to its high osmotic potential which restrict diffusion of nutrients and plant growth etc. (Bhatt and Srinivasa Rao 2005). Whereas, the tragacanth gum at $11 \mathrm{~g} / \mathrm{l}$ concentration had optimum lower osmotic potential and induced less water stress on growth and development of plants that allowed plants to take more nutrients from the gelling matrix compared to agar (control) resulting in better flourishing growth of plants. 
Usually, structural chromosomal variations are observed more frequently than numerical variations in regenerated plants (Kaeppler and Phillips 1993). It is very important to determine the genetic stability of the plants during or after tissue culture (García-Gonzáles et al. 2010). Bairu et al. (2011) explained that the degree of genomic instability depends on genotype, explant type, in vitro system, genome size, age of the culture, presence of an intermediate callus phase, and nature or concentration of the exogenous growth hormone used in nutrient media. Numerical and structural changes of chromosomes show major alterations to the genome and they are frequently generated during in vitro proliferation and differentiation (Neelakandan and Wang 2012). Karimi et al. (2016) observed that the explants productivity and growth obtained in tragacanth and agar combinations were better than those recorded on the control (agar) medium. However, they did not investigate the chromosome number alterations in carnation and miniature rose. Gernand et al. (2007) investigated structural variations in nuclei and chromosomes of cells derived from callus culture of Allium fistulosum using fluorescent in situ hybridization (FISH) technique. They determined that a high frequency of structural chromosome abnormalities was found by the loss of telomere-located $375 \mathrm{bp}$ repeats, chromosome fusion, and subsequent breakage fusion-bridge cycles. In vitro culture is considered to disrupt the balance of the genetic and epigenetic program of plant tissue and can cause to chromosomal and DNA sequence variations, methylation changes, transposon activation, and generation of somaclonal variants (Neelakandan and Wang 2012). The cytological studies demonstrated that no difference in ploidy level was obtained on the seedlings germinated on tragacanth and agar containing treatments.

This study presents a report for use of Astragalus microcephalus derived long term mechanically stable tragacanth gum gelling matrix in plant tissue culture studies for the first time. Visible and significant differences were noted on tobacco seedlings grown on tragacanth gum and agar. The results of this study suggests that tragacanth gum has great plasticity and could be successfully used without adversely affecting ploidy level of Nicotiana tabaccum cv. Samsun Canik plants. Tragacanth gum offers positive effects on growth of plants providing new cost effective matrix for tissue culture studies. However, further molecular genetics, epigenetic, and cytogenetic studies should be carried out to be sure on the effect of tragacanth gum.

\section{References}

Abbasi S and Rahimi S 2015. Persian gum. In: Encyclopedia of biomedical polymers and polymeric biomaterials. Mishra S (Eds), pp. 5919-5928. Taylor \& Francis LLC, New York, USA.

Anderson DWM 1989. Evidence for the safety of gum tragacanth (Asiatic Astragalus spp.) and modern criteria for the evaluation of food additives. Food Addit. Contam. 6: 1-12.

Atici T, Khawar KM, Ozel CA, Katircioglu H and Ates MA 2008. Use of psyllium (isubgol) husk as an alternative gelling agent for the culture of prokaryotic microalgae (Cyanobacteria) Chroococcus limneticus Lemmermann and eukaryotic green microalgae (Chlorophyta) Scenedesmus quadricauda (Turpin) Brebisson. Afr. J. Biotechnol. 7(8): 1163-1167.

Azarikia F and Abbasi S 2010. On the stabilization mechanism of dough (Iranian yoghurt drink) by gum tragacanth. Food Hydrocol. 24(4): 358-363.

Bairu MW, Aremu AO and Staden JV 2011. Somaclonal variation in plants: causes and detection methods. Plant Growth Regul. 63:147-173.

BakirY, EldemV, Zararsiz G and Unver T 2016. Global transcriptome analysisreveals differences in gene expression patterns between nonhyperhydric and hyperhydric peach leaves. Plant Genome 9(2): 1-9.

Balaghi S, Mohammadifar MA, ZargaraanA, Gavlighi HA and Mohammadi M 2011. Compositional analysis and rheological characterization of gum tragacanth exudates from six species of Iranian. Food Hydrocol. 25: 1775-1784. 
Bhatt RM and Srinivasa Rao NK 2005. Influence of pod load response of okra to water stress. Indian J Plant Physiol. 10: 54-59.

Bhowjwani S andDantu PK 2013. Plant Tissue Culture: An Introduction Text. New Delhi; New York, Springer.

Congard B, Beaujard F and Viemont JD 1986. Les bruyeres in vitro VI Croissance de Calluna vulgaris sur milieu strictement nitrique ammoniacal et cinetique du $\mathrm{pH}$ en fonction du development des plantes. Can. J. Bot. 64: 959-964.

Dalvi SG, Gudhate PP, Tawar PN and Prasad DT 2011. Low cost support matrix for potato micropropagation. Potato J. 38(1): 47-50.

Debergh PC 1983. Effects of agar brand and concentration on the tissue culture medium. Physiol. Plant. 59: 270-276.

Delease P 2008. Foam-creating compositions, foaming beverage compositions, and methods of preparation thereof. U.S. Patent Application No. 11/775,932.

Dougall DK1980. Nutrition and metabolism. In: Plant Tissue Culture as a Source of Biochemicals. Staba EJ (Eds), pp. 21-58. CRC Press, FL.

García-Gonzáles R, Quiroz K, Carrasco B and Caligari P 2010. Plant tissue culture: Current status, opportunities and challenges. Cienc. Investing. Agrar. 37(3): 5-30.

Gernand D, Golczyk H, Rutten T, Ilnicki T, Houben A, Joachimiak AJ 2007. Tissue culture triggers chromosome alterations, amplification, and transposition of repeat sequences in Allium fistulosum. Genome 50(5): 435-442.

Glicksman M 1969. Gum technology in the food industry. New York: Academic Press. Food Hydrocol. 2: 417-23.

Goel MK, Kukreja A K and Khanuja SP 2007. Cost-effective approaches for in vitro mass propagation of Rauwolfia serpentina Benth. Ex Kurz. Asian J. Plant Sci. 6: 957-961.

Henderson WE and Kinnersley AM 1988. Corn starch as an alternative gelling agent for plant tissue culture. Plant Cell Tiss. Org. Cult. 15: 17-22.

Hussien FA, Osman MA and Idris TIM 2014. The influence of liquid media support, gelling agents and liquid overlays on performance of in vitro cultures of ginger (Zingiber officinale). IJSRP. 4(10): 1-5.

Imeson A 1992. Exudate gums. In: Thickening and gelling agents for food. Imeson A, Eds pp. 66-97, Glasgow: Blackie Academic and Professional.

Jain N and Babbar SB 2002. Gum katira - A cheap gelling agent for plant tissue culture media. Plant Cell Tiss. Org. Cult. 71: 223-229.

Jain N and Babbar SB 2005. Guar gum and isubgol as cost-effective alternative gelling agents for in vitro multiplication of an orchid Dendrobium chrysotoxum. Curr. Sci. 88: 292-294.

Kaeppler SM and Phillips RL1993. DNA methylation and tissue culture-induced variation in plants. In Vitro Cell. Dev. Biol. 29:125-130.

Karimi S, Salehi H and Ashiri F 2016. Tragacanth, a Novel and Cheap Gelling Agent in Carnation and Miniature Rose Tissue Culture Media. Journal of Ornamental Plants 6(4): 253-260.

Kevers C, Franck T, Strasser RJ, Dommes J and Gaspar T 2004. Hyperhydricity of micropropagated shoots: Atypically stress-induced change of physiological state. Plant Cell Tiss. Org. Cult. 77(2): 181-191.

Kuria P, Demo P, Nyende AB and Kahangi EM 2008. Cassava starch as an alternative cheap gelling agent for the in vitro micro-propagation of potato (Solanum tuberosum L.). Afr. J. Biotechnol.7(3): 301-307.

Kwoseh CK, Asomani-Darko Mand Adubofour K 2012. Cassava starch-agar blends as alternative gelling agent for mycological culture media. Bots. J. Agric. Appl. Sci. 8(1): 8-15.

Lapasin R and Pricl S 1999. Rheology of polysaccharide systems. In: Rheology of industrial polysaccharides: Theory and applications. Eds. R. Lapasin, pp. 250-309. United States of America, an Aspen Publication.

Lee WK, Lim YY, Leow A TC, Namasivayam P, Abdullah JO and Ho CL 2017. Factors affecting yield and gelling properties of agar.J. Appl. Phycol. 29(3): 1527-1540. 
Mantell CL 1947. The water-soluble gums. New York: Reinhold Pub. Corp.

McLachlan J 1985. Macroalgae (seaweeds): Industrial sources and their utilization. Plant Soil. 89: 137-157.

Meng H, Janssen PML, Grange RW, Yang L, Beggs AH, Swanson LC,. Cossette SA, Frase A, Childers MK, Granzier HG, GussoniE, Lawlor MW 2014. Tissue triage and freezing for models of skeletal muscle disease. J. Vis. Exp. 89: 51586. doi:10.3791/51586.

Mohamadnia Z, Zohuriaan-Mehr MJ, Kabiri K and Razavi-Nouri M 2008. Tragacanth gum-graftpolyacrylonitrile: synthesis, characterization and hydrolysis. J. Polym. Res. 15(3): 173-180.

Mortensen A, Aguilar F, Crebelli R, Di Domenico A, Frutos MJ, Galtier P and Lindtner 2017. Re-evaluation of tragacanth (E 413) as a food additive. EFSA Journal 15(6): 10.2903/j.efsa. 2017.4789.

Nairn BJ, Furneaux RH and Stevenson TT 1995. Identification of an agar constituent responsible for hydric control in micropropagation of radiata pine. Plant Cell Tiss. Org. Cult. 43: 1-11.

Neelakandan AK and Wang K 2012. Recent progress in the understanding of tissue culture-induced genome level changes in plants and potential applications. Plant Cell Rep. 31(4): 597-620.

Nussinovitch A 1997. In: Hydrocolloid applications: Gum technology in the food and other industries. pp. 125-39. London: Blackie Academic \& Professional.

Ozel CA, Khawar KM and Arslan O 2008. A comparison of the gelling of isubgol, agar and gelrite on in vitro shoot regeneration and rooting of variety Samsun of tobacco (Nicotiana tabacum L.) Sci. Hortic. 117: 174-181.

Parashar B, Kabra A and Chandel A 2013. Formulation and evaluation of gel containing miconazole nitrate an antifungal Agent. IJPRR 2(6): 18-28.

Phillips GO and Williams PA 2009. Handbook of Hydrocolloids. 2nd Edition. pp 948. CRC Press, Boca Raton Boston New York Washington, DC. Woodhead Publishing Limited. Oxford Cambridge New Delhi.

Rousk J, Brookes PC and Bååth E 2009. Contrasting soil pH effects on fungal and bacterial growth suggest functional redundancy in carbon mineralization. Appl. Environ. Microbiol. 75: 1589-1596.

Saglam S and Ciftci CY 2010. Effects of Agar and isubgol on adventitous shoot regeneration of woad (Isatis tinctoria). Int. J. Agric. Biol. 12(2): 281-285.

Schwarz TW, Levy G and Kawagoe HH 1958. Tragacanth solutions. III. The effect of pH on the stability. The Scientific Edition of the Journal of the American Pharmaceutical Association 47: 695-696.

Shi X, Yang L, Yan G and Du G 2017. Medium pH between 5.5 and 7.5 has minimal effects on tissue culture of apple. Hort. Sci. 52(3): 475-478.

Sudha PN 2017. In: Industrial Applications of Marine Biopolymers. Eds. P. N. Sudha, K. Sangeetha, T. Gomathi. CRC Press. Chapter 1. Introduction to marine biopolymers. ISBN: 9781315313535.

Sulusoglu M 2014. Effects of agar types on rooting performance in tissue culture: Sample of quince a rootstock cultures. TURKJANS 1: 957-963.

Teimouri S, Abbasi S and Sheikh N 2016. Effects of gamma irradiation on some physicochemical and rheological properties of Persian gum and gum tragacanth. Food Hydrocoll. 59: 9-16.

Tyagi RK, Agrawal A, Mahalakshmi C, Hussain Z and Tyagi H 2007. Low-cost media for in vitro conservation of turmeric (Curcuma longa L.) and genetic stability assessment using RAPD markers. In Vitro Cell. Dev. Biol. Plant 43(1): 51-58.

Van den Dries N, Giannì S, Czerednik A, Krens FA, and de Klerk GJM 2013. Flooding of the apoplast is a key factor in the development of hyperhydricity. J. Exp. Bot. 64(16): 5221-5230.

Weiping W 2000. Tragacanth and Karaya. In: Handbook of hydrocolloids. Phillips GO and Williams PA (Eds), pp. 231-46.1st ed. Boca Raton CRC Press.

Xiao K, YuL and $\mathrm{Xu} \mathrm{J}$ 2014. $\mathrm{pH}$, nitrogen mineralization, and $\mathrm{KCl}$-extractable aluminum as affected by initial soil $\mathrm{pH}$ and rate of vetch residue application: results from a laboratory study. J. Soil. Sed. 14(9): 1513-1525. 